\title{
Transgresiones mediales: Terry y los piratas como franquicia
}

\author{
Francisco Sáez de Adana
}

\author{
Doctorando de Comunicación, Universitat Pompeu Fabra \\ Instituto Franklin de Estudios Norteamericanos, Universidad de Alcalá
}

Francisco Sáez de Adana Herrero es profesor en la Universidad de Alcalá. Realiza el doctorado en el Departamento de Comunicación de la Universidad Pompeu Fabra sobre la obra de Milton Caniff. Es subdirector del Instituto Franklin de Estudios Norteamericanos de la Universidad de Alcalá, donde colabora en el estudio y análisis del cómic como medio de expresión. Relacionado con este ámbito, ha publicado cinco capítulos en libros así como siete artículos en revistas, tanto nacionales como internacionales. Impartió un seminario sobre Milton Caniff y la cultura americana en la Universidad de Salerno y ha sido invitado para dar conferencias sobre ese mismo autor, y sobre tiras de prensa en general, por el Salón del Cómic de Barcelona, el Festival Internacional del Cómic de Santiago de Chile y la Universidad de Buenos Aires. Desde el año 2014, organiza un curso de verano dedicado al estudio del cómic en la Universidad de Alcalá. Es editor de Ediciones Marmotilla, editorial dedicada a la publicación de estudios teóricos sobre el medio de la historieta.

Fecha de recepción: 12 de octubre de 2017

Fecha de aceptación definitiva: 7 de noviembre de 2017 


\title{
Resumen
}

En este artículo se pretende realizar una perspectiva histórica respecto a uno de los fenómenos más generalizados actualmente, el de la creación de narraciones intermediales o transmediales basadas en personajes provenientes del cómic. Se trata de comprobar cómo la ubicuidad de determinados personajes que son adaptados o recreados en diferentes medios audiovisuales, y cuya imagen es un evidente atractivo comercial, tiene un precedente claro en los años dorados de las tiras de prensa, correspondientes a la primera mitad del siglo XX. Para ello, se analizan las recreaciones, transposiciones y extensiones de una de las series más relevantes de ese período, Terry y los piratas.

Palabras clave: Terry y los piratas, Milton Caniff, tiras de prensa, adaptaciones, transgresiones mediales.

\begin{abstract}
This paper intends to perform a historical perspective on one of the most generalized current phenomena, as it is the creation of intermedia or transmedia narratives based on characters coming from the comics. The aim is to verify how the ubiquity of certain characters that are adapted or recreated in different audiovisual media, and whose image is an evident commercial attraction, has a clear precedent in the golden years of the comic strips, corresponding to the first half of the 20th century. With this goal, the recreations, transpositions and extensions of one of the most relevant series of that period, Terry and the pirates, are analyzed.
\end{abstract}

Keywords: Terry and the Pirates, Milton Caniff, comic strips, adaptations, medial transgressions.

\section{Cita bibliográfica}

SÁez de Adana, F., «Transgresiones mediales: Terry y los piratas como franquicia», en Cuco, Cuadernos de cómic, n. ${ }^{\circ} 9$ (2017), pp. 53-73. 


\section{Introducción}

En el año 1946, la editorial Simon and Schuster publicó un libro, titulado While You Were Gone. A Report in War Life in the United States, ${ }^{1}$ en el que diferentes autores mostraban su visión de lo que había sido la vida en los Estados Unidos durante los años de la Segunda Guerra Mundial. El objetivo era proporcionar información a los soldados que habían estado movilizados fuera de su país durante estos años, con el fin de que su adaptación a la vida civil fuera más sencilla. En ese libro se incluían capítulos dedicados a todos los aspectos de la vida en los Estados Unidos que se consideraban importantes en esa época. Así, tenemos artículos relacionados con el ámbito de la política, de la economía, de las relaciones sociales y de la cultura. En este último ámbito se encuentran artículos dedicados al cine, al teatro, a la música y, con el mismo grado de importancia, al cómic. Aunque el capítulo se titula directamente «The Comics», se centra exclusivamente en las tiras de prensa, lo que demuestra que este tipo de cómic era el único considerado con la suficiente relevancia, tanto artística como social, para ser incluido al mismo nivel que otros ámbitos de la vida cultural estadounidense. El contenido de ese capítulo incluye una lista con las diez series publicadas en prensa más populares de la época. Las cifras de lectores van desde los veintiséis millones de seguidores de The Gumps, situada en el número 10, hasta los cuarenta millones de Joe Palooka, en el número uno. Es decir, al menos diez series de cómic de prensa tenían un número de lectores superior a los veinticinco millones. Diferentes estudios ${ }^{2}$ afirman que esta elevada audiencia no fue un fenómeno pasajero, sino que se mantuvo durante prácticamente toda la primera mitad del siglo xx. Estamos, por tanto, durante este periodo, ante un medio de comunicación de masas.

Esta importancia del cómic de prensa durante un periodo de tiempo tan prolongado podría hacer creer que una disciplina como los estudios de cómic, relativamente tan reciente y que cuyo reconocimiento, desde el punto de vista académico, no ha sido algo inmediato, dedicaría un espacio al cómic de prensa en los Estados Unidos durante el periodo histórico ya mencionado, por su importancia a nivel de penetración entre el público y su trascendencia a nivel social, algo por lo que esta disciplina lleva luchando desde sus inicios. Sin embargo, el despegue de los estudios de cómic como disciplina en los últimos años - que tuvo uno de sus hitos en la creación, casi simultánea en el año 2010, de dos revistas académicas dedicadas a este medio, Studies in Comics y Journal of Graphic Novels and Comics (indexada en Scopus) - no implica que entre todos los cómics que se están estudiando se esté dedicando un espacio significativo a las tiras de prensa. Desde su fundación, Journal of Graphic Novels and Comics ha publicado, a fecha de junio de 2017, 151 artículos, de los cuales solamente siete han estado dedicados a las tiras de prensa. En el caso de Studies in Comics, de sus 114 artículos hasta esa misma fecha, solo dos se han dedicado a este tipo de publicación. Todo lo cual resulta difícil de entender si nos atenemos al factor de la repercusión social, mencionado anteriormente.

${ }^{1}$ Goodman, J. (ed.). While You Were Gone. A Report in War Life in the United States. Nueva York, Simon and Schuster, 1946.

${ }^{2}$ Ver, entre otros, Waugh, C. The Comics. Jackson, University Press of Mississippi, 1947 y Coma, J. (Ed.) Historia de los cómics, vol. 1. Barcelona, Toutain, 1984. 
Uno de los aspectos más interesantes a la hora de estudiar la repercusión social de estas series es analizar los productos derivados de las mismas que aparecían en el mercado. Christina Meyer se refiere a estos productos, en su análisis de las obras de teatro y los juguetes derivados de The Yellow Kid, como «transgresiones mediales», ${ }^{3}$ y argumenta que «los movimientos y migraciones de The Yellow Kid en, entre y hacia diferentes medios señalan la especial significación de la figura cómica en relación con el centro de atención que merece actualmente la condición de medialidad y materialidad de los cómics contemporáneos y de otras formas de narrativa gráfica». ${ }^{4}$ Analizando la adaptación y transposición de The Yellow Kid a otros medios, Meyer pretende «ofrecer una perspectiva histórica de esta evolución»..$^{5}$ El trabajo de Meyer es un excelente punto de partida para mostrar esta perspectiva histórica, ya que analiza el periodo correspondiente a finales del siglo XIX a través de uno de los personajes más populares en esa época. ${ }^{6}$ Es ya conocida la historia del conflicto entre Joseph Pulitzer y William Randolph Hearst por la inclusión de las historias de este personaje en las páginas de sus periódicos, lo que dio lugar al término de periodismo amarillo y que es la muestra más palpable de la popularidad de este personaje. ${ }^{7}$ Sin embargo, si se quiere continuar con ese análisis histórico hay que considerar el salto que supone para el cómic de prensa, a nivel de repercusión, el nacimiento de las agencias. Este fenómeno supuso que las principales series pasaran de publicarse a nivel local a ser distribuidas a nivel nacional, permitiendo que paulatinamente fueran alcanzando cifras de lectores como las mencionadas anteriormente. Por eso, es interesante realizar un estudio histórico similar al que hace Meyer en su artículo para alguna de las series de mayor éxito en los años treinta y cuarenta, periodo dorado de las tiras de prensa distribuidas por agencia.

Con esta finalidad, en este artículo se realiza un estudio de los productos derivados de la serie Terry y los piratas durante los años en los que su creador, Milton Caniff, estuvo al frente de la misma, es decir, desde su creación en 1934 hasta el año 1946, en el que deja la serie en manos de George Wunder. La elección de Terry y los piratas viene marcada por dos circunstancias: por un lado, la posibilidad de acceder a buena parte del material que se comentará en el artículo, ya que se conserva en The Billy Ireland Cartoon Library and Museum de Ohio State University, institución a la que el autor donó todo su archivo unos años antes de su muerte. Sin embargo, esto no sería suficiente si no existiera la segunda circunstancia, y es que se trata de una serie con una repercusión importante durante esos años. En la lista de series más leídas durante los años de la guerra, Terry y los piratas aparece en el quinto lugar, con un número de lectores diarios de aproximadamente treinta y un millones. Se trata de cifras importantes, que están amplificadas por la consideración de que Terry era una de las series de más repercusión y mayor relevancia social durante esos años, como recogen los

\footnotetext{
${ }^{3}$ Meyer, C. «Medial transgressions: comics - sheet music - theatre - toys», en Journal of Graphic Novels and Comics, vol. 7, n. 3 (2016), p. 294.

${ }^{4}$ Idem.

5 Idem.

${ }^{6}$ No en vano, durante mucho tiempo, el origen del cómic se fijó en una página de The Yellow Kid, aspecto que hoy en día está más discutido.

7 Waugh, C. Op. cit., p. 1.
} 
trabajos de diversos autores. ${ }^{8}$ Probablemente, la prueba más importante de esta afirmación es que el autor del capítulo dedicado a los cómics en While You Were Gone no sea otro que Milton Caniff. El hecho de que el editor de ese libro considerara que Caniff era la persona más adecuada para narrar la importancia del cómic en la sociedad durante esa época es una muestra palpable de la trascendencia social que tenían este autor y, en consecuencia, su serie.

Este artículo se centrará, por tanto, en el análisis de las principales derivaciones o transgresiones mediales de Terry y los piratas que surgieron en otros medios, con el objetivo de realizar una perspectiva histórica de la relevancia de las tiras de prensa en la primera mitad del siglo xx. Estas derivaciones pueden considerarse como adaptaciones de la serie principal, en este caso la tira de prensa, a otros medios diferentes. Por ese motivo, a la hora de contribuir a la perspectiva histórica iniciada por Mayer respecto a la condición de medialidad y materialidad del cómic, se considerarán estas transgresiones mediales como diferentes adaptaciones de la obra original. En este sentido, Linda Hutcheon clasifica la adaptación en tres grupos: actos creativos de apropiación del texto original; transposiciones, donde se cuenta prácticamente la misma historia; y extensiones o productos derivados del texto adaptado. ${ }^{9}$ Aunque como la propia Hutcheon reconoce, estos tres grupos no son excluyentes y puede haber obras que incluyan elementos de varios de esos grupos, por lo que la estructura de este artículo tomará esa clasificación como punto de partida.

\section{Actos creativos derivados del texto original}

En lo que respecta a los medios que tomaron la serie original como arranque para realizar su propia visión de la misma, se deben mencionar, fundamentalmente, las adaptaciones que se realizaron en forma de seriales, tanto en el cine como en la radio, que, junto con los periódicos, eran los medios principales de entretenimiento en la época analizada en este estudio. ${ }^{10}$

\section{El serial cinematográfico}

En el año 1940, Columbia Pictures empezó a distribuir en los cines norteamericanos un serial cinematográfico con un total de quince episodios de aproximadamente veinte minutos de duración. El serial fue el resultado de un proceso de más de dos años, en los que la productora mantuvo una constante correspondencia con Caniff para ponerse de

\footnotetext{
${ }^{8}$ Ver, entre otros, Coma, J. Cuando la inocencia murió. Ensayo sobre la obra de Milton Caniff "Terry y los piratas". Madrid, Ediciones Eseuve, 1986; Fornaroli, E. Milton Caniff. Un filmico pennello tra il nero e il merletto. Florencia, La Nova Italia, 1988; Harvey, R. C. Meanwhile... A biography of Milton Caniff, creator of Terry and the Pirates and Steve Canyon. Seattle, Fantagraphics Books, 2007; Hayward, J. P. Consuming Pleasures: Active Audiences and Serial Fictions from Dickens to Soap Opera. Lexington, University Press of Kentucky, 1997.

9 Hutcheon, L. A Theory of Adaptation. New York, Routledge, 2006, p. 8.

${ }_{10}$ Bird, C. The Invisible Scar. New York, David McKay Company, 1966, pp. 61-62.
} 
acuerdo a la hora de llevar a cabo la producción. ${ }^{11}$ Caniff consideraba que el serial podía ser fundamental para aumentar la repercusión de su serie, por lo que estaba muy preocupado por cómo se iba a llevar a cabo la adaptación de su obra y quería mantener un cierto control creativo sobre el resultado final. Sin embargo, el autor no poseía los derechos de la serie $\mathrm{e}^{12} \mathrm{y}$, por motivos presupuestarios entre otros, finalmente se hizo caso omiso a las sugerencias de Caniff, negándole cualquier posibilidad de intervenir en los guiones del serial. Una vez finalizado este, la publicidad de la época (FIG. 1) resumía de esta manera el argumento:

El joven explorador Terry Lee y su compañero adulto, Pat Ryan, llegan a las selvas asiáticas en busca del padre de Terry, el Dr. Herbert Lee. El mayor Lee es un arqueólogo y líder de una expedición científica que busca evidencia de una civilización perdida. Pronto, Terry descubre que su padre ha sido secuestrado por una banda pirata armada conocida como los Tiger Men. La banda está dirigida por el malvado Maestro Fang, un señor de la guerra local que controla a la mitad de los nativos y mantiene apartados a los colonos blancos con miedo. Fang está buscando las riquezas escondidas bajo el Sagrado Templo de Mara. Terry conoce a Dragon Lady, que está decidida a que su reino no sea invadido. Atacado por Fang, su secuaz Stanton y los Tiger Men, Terry y Pat intentan valerosamente localizar al desaparecido Dr. Lee, descubrir los secretos de la civilización perdida y recuperar el tesoro escondido de Mara. Después de unir fuerzas con Connie, Normandie Drake y Dragon Lady, los héroes tienen innumerables aventuras variadas en el ambiente inhóspito. ${ }^{13}$

Se trata, por tanto, de una recreación donde los autores del serial se apropiaron de la historia y en la que no existe ningún parecido con el devenir de la serie en ese momento, donde sus personajes estaban ya inmersos en la guerra chino-japonesa. Ni siquiera hay ninguna similitud con los comienzos de la tira, donde el tono de aventura era mayor, ya que los personajes y la historia se apartan totalmente de la idea original del autor, entre otras cosas, al alejarse del escenario principal de la historia, China, tan importante para la ambientación de la misma. Obviamente, Caniff no pudo ocultar su disgusto por el resultado final cada vez que le preguntaban por el serial a lo largo de su vida:

Ahí sí que se tomaron una excesiva libertad en la caracterización. Por ejemplo, siempre había
planeado que el gran enfrentamiento de todos los tiempos en la tira sería cuando Big Stoop se
encontrara con Dragon Lady. Ella había hecho que le cortaran la lengua cuando era un niño, y era
una joven princesa mezquina, y la única persona en el mundo a la que temía era a Big Stoop. Bien,
ahora han hecho que Big Stoop hable en la versión del sábado por la tarde, y han estropeado todo
mi plan para el futuro. No importa mucho porque nadie recuerda muy bien estas cosas, pero me
molestó. Hice una protesta formal, pero no fue a ninguna parte.

11 VV.AA. Terry Movie Correspondence Stills, 1939-1940. Archivo de Milton Caniff en Billy Ireland Cartoon Library and Museum, Columbus, Ohio (EE. UU.). Box MAC.P88 / Folder 6.

12 Milton Caniff había recibido el encargo de crear Terry y los piratas por la agencia de noticias Chicago Tribune New York News Syndicate, que en todo momento mantuvo la propiedad de la serie.

13 S. A. Folleto publicitario del serial cinematográfico. Archivo de Milton Caniff en Billy Ireland Cartoon Library and Museum, Columbus, Ohio (EE. UU.). Box MAC.P88 / Folder 6. 


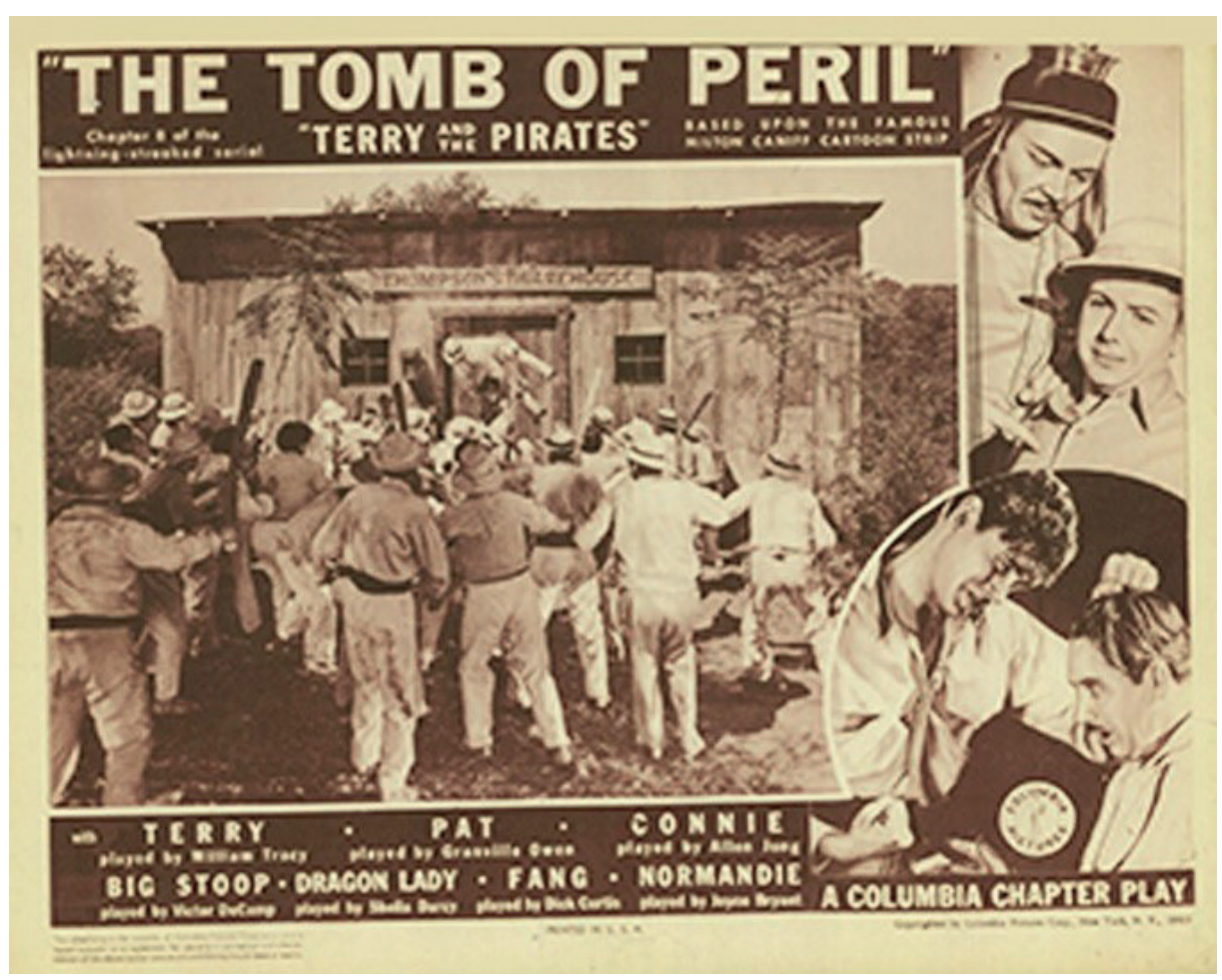

FIG. 1. Imagen promocional del serial cinematográfico de Terry y los piratas. Fuente: VV.AA. Terry movie correspondence stills, 1939-1940. Archivo de Milton Caniff en Billy Ireland Cartoon Library and Museum, Columbus, Ohio (EE. UU.). Box MAC.P88 / Folder 6.

Columbia y muchos otros estudios solían ser una máquina de producir esos seriales de sábado por la tarde para niños, y realmente les importaban poco. Me siguieron enviando los guiones, pero ni me molesté en leerlos. Ni siquiera me molesté en ir a ver las películas después de la primera. Me salí de la primera y nunca vi ninguna otra después de aquella, lo que fue una pena porque tenía que haber sido una operación basada en la colaboración por ambas partes. Simplemente, estaba mal hecho, en mi opinión. Los actores trabajaron duro, pero a la gente del serial no le importaba. Simplemente, lo trataron como una fábrica de salchichas.

Eso no es cierto para la radio. Era mucho más fiel a la idea básica de la tira y a mis ideas sobre la caracterización. En la versión cinematográfica, por ejemplo, la chica que interpretaba a Dragon Lady parecía tener veinte años. Dragon Lady no tiene edad. Ha estado aquí siempre y siempre fue aquella mujer más mayor, más sabia, y no una jovencita amiga del productor. No debería decir esto. No sé de quién era amiga. ${ }^{14}$

Aunque Hutcheon dice que, en la adaptación, las «versiones múltiples existen lateralmente, y no verticalmente», ${ }^{15}$ parece bastante claro que la concepción que Caniff tenía respecto a

\footnotetext{
${ }^{14}$ Новак, C. J. «Terry and the Pirates, the Serial», en Caniffites, n. 37 (1989), p. 8.

15 Hutcheon, L. Op. cit., p. XiII.
} 
Terry era una concepción vertical, donde el orden jerárquico superior debería estar definido por la tira de prensa.

En el ámbito de las adaptaciones cinematográficas, se debe mencionar el proyecto no realizado de Douglas Fairbanks Jr., quien en 1945, cuando todavía estaba en el ejército luchando en la Segunda Guerra Mundial, viendo que la guerra se acercaba a su fin y pensando en futuros proyectos después del conflicto, se puso en contacto con Caniff para comentarle su interés por realizar una adaptación al cine de Terry y los piratas. En todo momento, Fairbanks quería inmiscuir a Caniff en el proyecto y contar con un presupuesto adecuado para llevar a cabo la adaptación de forma totalmente satisfactoria y no repetir el fracaso del serial de Columbia, como muestran las cartas que el director y productor le envió a Caniff, con frases como esta: «tenemos muchas y grandes ambiciones para Terry, y nos vamos a apoyar en ti para todo lo que estés dispuesto». ${ }^{16}$ Hubo varias dificultades que impidieron la realización final de la película, siendo las más importantes la imposibilidad de encontrar la financiación por parte de Fairbanks y el hecho de que Caniff sabía que su contrato en Terry acababa a finales de 1946, por lo que si quería estar involucrado en el proyecto, este debía realizarse en poco más de un año, circunstancia complicada por la situación de Fairbanks en el ejército y por las cuestiones presupuestarias ya mencionadas. Sin embargo, Fairbanks compró los derechos de la serie, y en el año 1946 se realizó un guion para la película ${ }^{17}$ por parte de John McClain, ${ }^{18}$ donde se cuenta una aventura de Terry como piloto de Air Cathay después de la guerra, siguiendo las líneas argumentales de la tira de prensa durante esos años. La película nunca se llegó a realizar, pero Fairbanks mantuvo los derechos pensando en rodarla algún día, hasta que en el año 1951 los vendió a Sam Katzman, que a su vez se los cedió a Don Sharpe Enterprises para lo que resultaría ser la serie televisiva del personaje. La serie, de dieciocho episodios de media hora, se emitió entre el 26 de junio y el 21 de noviembre de 1953, y su tono está mucho más cercano a las historias que George Wunder escribió a partir de finales de 1946 que a la dirección que Caniff había fijado para la tira.

\section{El serial radiofónico}

Terry y los piratas comenzó emitiéndose en la radio el 1 de noviembre de 1937 en la cadena NBC Red, tres veces a la semana bajo el patrocinio de Dari-Rich. Estuvo en esta cadena hasta el 1 de junio de 1938, y el 26 de septiembre del mismo año cambió a la cadena NBC Blue, donde se emitió una temporada más, hasta el 22 de marzo de 1939. Después de una

${ }^{16}$ Fairbanks J. R., D. Carta dirigida a Milton Caniff, 17 de marzo de 1940. Archivo de Milton Caniff en Billy Ireland Cartoon Library and Museum, Columbus, Ohio (EE. UU.). Box MAC.P88 / Folder 9.

17 Este guion se conserva en VV.AA. Terry Movie Correspondence, October 1946-1949. Archivo de Milton Caniff en Billy Ireland Cartoon Library and Museum, Columbus, Ohio (EE. UU.). Box MAC.P88 / Folder 10.

${ }_{18}$ John McClain fue un guionista de Hollywood que tuvo una corta carrera entre los años 1940 y 1942, donde guionizó cinco películas: My Favourite Wife de Garson Kanin (1940), Turnabout de Hal Roach (1940), The Wild Man of Borneo de Robert B. Sinclair (1941), Lady Be Good de Norman Z. MacLeod (1942) y Cairo de W. S. VanDyke (1942). 
ausencia de las ondas de dos años, volvió poco antes del ataque a Pearl Harbor, emitiéndose en el medio oeste de Estados Unidos en el Chicago Tribune WGN. Esa serie, patrocinada por Libby (FIG. 2), una marca de conservas, se emitió cinco días a la semana desde el 16 de octubre de 1941 al 29 de mayo de 1942. Finalmente, se retomó el 1 de febrero 1943 en ABC Blue Network, donde fue patrocinado por Quaker Oats, una marca de cereales, hasta su cancelación el 30 de junio de 1948. Sus mejores resultados de audiencia se obtuvieron durante los años de la guerra, decayendo esta progresivamente en los años posteriores a la contienda.

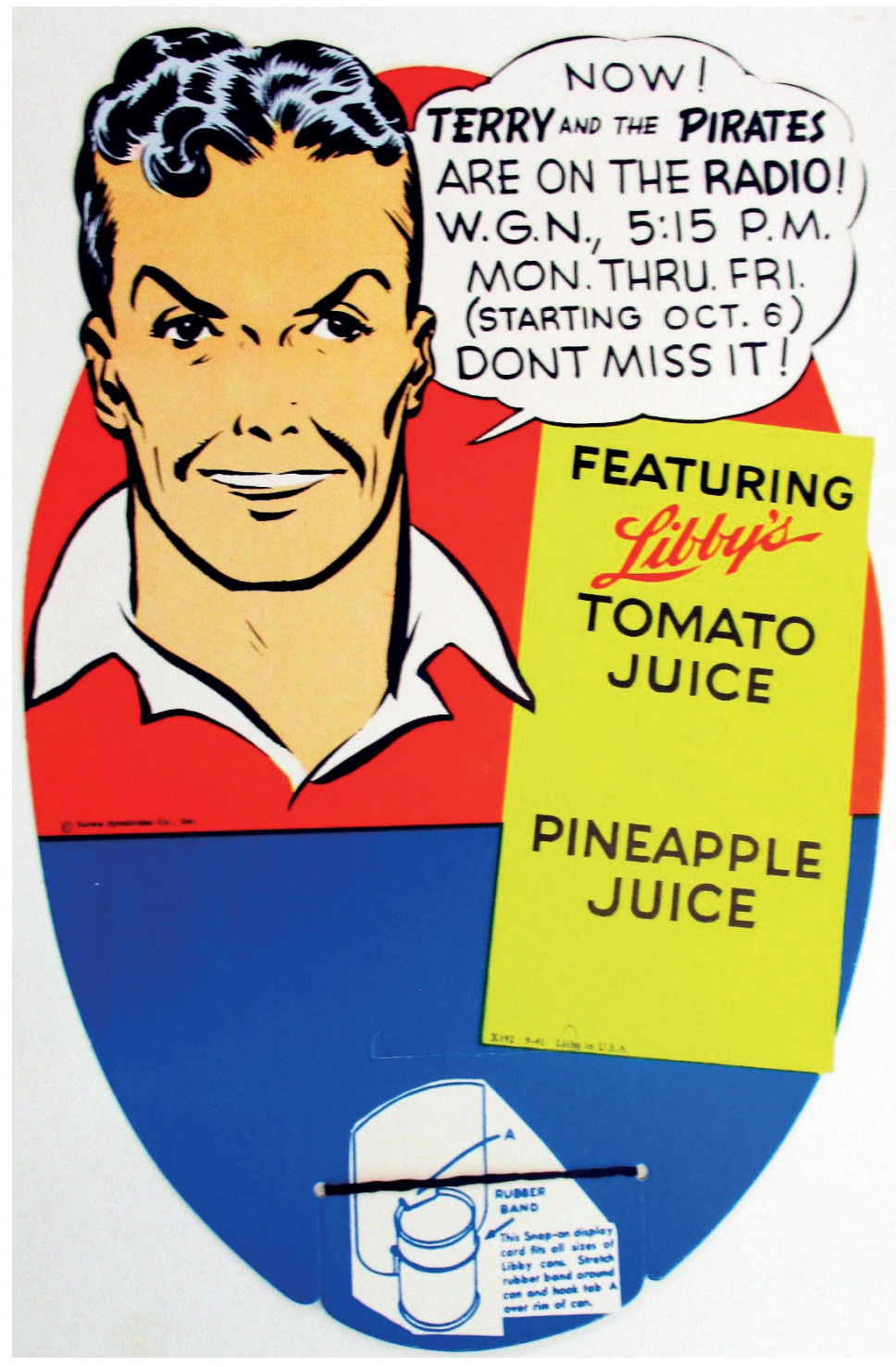

FIG. 2. Imagen promocional del serial radiofónico de Terry y los piratas con el patrocinio de Libby. Fuente: VV.AA. Terry Radio. Archivo de Milton Caniff en Billy Ireland Cartoon Library and Museum, Columbus, Ohio (EE. UU.). Box MAC.P88 / Folder 11. 
Fue una de las primeras aventuras juveniles que hicieron campaña contra el fascismo, y mantuvo su advertencia de la existencia de grupos enemigos aislados hasta 1946. Una vez que se declaró la guerra y se formaron los batallones, el escritor Albert Baker no perdió tiempo en realizar el casting de Terry y sus compañeros para introducirlos en la batalla. Pese a que operaba fundamentalmente en Oriente, es irónico que los mayores enemigos de Terry en tiempos de guerra eran los nazis, chaquetas marrones enviados desde Berlín para «supervisar las operaciones en el Pacífico» o algo así. En 1943, Terry formó equipo con su vieja enemiga, Dragon Lady (trabajando supuestamente para los chinos), para destruir un almacén japonés, escondido en una plantación del río Amarillo bajo la supervisión del malvado Baron von Krell. Para Terry, esta no fue una alianza fácil; no sabía que la infame Dragon Lady le apuñalaría por la espalda y se pasaría al otro lado. En 1944, Pat Ryan y Terry fueron seleccionados por el Servicio Secreto Británico para hacerse pasar por oficiales nazis en una peligrosa misión hacia Tokio. Hasta en 1945, con Alemania casi de rodillas, todavía estaban luchando contra un grupo de nazis, en este caso trabajando en Calcuta. ${ }^{19}$

En 1946, la relación con la guerra desapareció, Dragon Lady regresó a su organización de bandidos y Terry y sus amigos lucharon contra malvadas organizaciones en Extremo Oriente. La magia se desvaneció y las audiencias cayeron estrepitosamente.

Dragon Lady fue la enemiga más formidable de Terry, pero nada revivió la emoción de los años de la guerra, cuando el anunciante Douglas Browning (...) mantenía el tema patriótico del programa hasta el final, cuando cerraba con su «victograma» diario del estilo:

Paper is a mighty weapon

Haul it in, keep smatrly steppin'.

Turn in every scrap you can,

To lick the Nazis and Japan. ${ }^{20}$

Milton Caniff hizo algunos comentarios sobre el serial radiofónico cuando David Folkman le entrevistó en 1986:

No estuve involucrado [en el serial radiofónico] de ninguna manera. Hicieron un buen trabajo con lo que tenían y, en lo que respecta a los argumentos, iban mucho más rápido que yo en la tira.

Pat Ryan [en la radio] sonaba como Pat Ryan, y Dragon Lady sonaba como Dragon Lady, aunque nadie los había oído antes, pero el diálogo estaba escrito cuidadosamente. Trataron de mantener el espíritu de los personajes.

${ }_{19}$ Dunning, J. Tune in Yesterday: The Ultimate Encyclopedia of Old-Time Radio, 1925-1976. New Jersey, Prentice Hall, 1976, p. 594.

20 Idem. 
Escuchaba el serial todos los días. No creo que ayudara a conseguir nuevos periódicos que publicaran la tira, por una razón que hoy en día puede parecer extraña y es que los editores de periódicos odiaban la radio en aquel entonces. Incluso recibí, cuando fue anunciado que saldría en antena, una carta de un editor que decía: «¿Me puedes avisar cuando Terry salga al aire para poder cancelar la tira?». Así de profundamente odiaban la radio. Y no era una cuestión de competencia. Creo que ayudó a la tira de prensa. Cualquier mención favorable de una cabecera en otro medio es buena. No hace más que mantener el nombre a los ojos del público, incluso si la interpretación no es exactamente la misma; mientras escriban el nombre correctamente, es buen material para la promoción y publicidad sobre la existencia de la tira.

Muchos periódicos se aprovecharon de ello y lo resaltaron junto con el hecho de que ellos publicaban la tira diariamente. Pero nunca se sabrá, porque ahora la televisión ha cambiado todo. Y no podemos recordar el efecto que la radio tenía en ese aspecto. ${ }^{21}$

De nuevo, la concepción vertical de la adaptación de Caniff, con la serie de los periódicos como elemento dominante, es fundamental a la hora de establecer su juicio cualitativo de la recreación de Terry en otros medios. Hay dos aspectos interesantes a la hora de analizar el serial radiofónico. Por un lado, la presencia constante de un patrocinador en la serie. En episodios de aproximadamente quince minutos, se dedicaban dos al principio y otros dos al final, quedando reducidas las andanzas de Terry a aproximadamente once minutos por episodio, pero eso demuestra la fuerza de la marca Terry como reclamo comercial, de forma similar a lo que sucede con las franquicias en nuestros días. Por otro lado, la serie estaba supuestamente dirigida al público infantil, todo lo contrario de la idea que tenía Caniff con respecto a su serie de cómics. De esta manera, cuando se llevaban a cabo las mediciones de audiencia, estas se comparaban con las de otras series dirigidas a este tipo de público, llegando en algunos momentos a ser la serie con más oyentes de entre todas las consideradas infantiles. En todo caso, esta idea vertical de Caniff tiene su justificación si consideramos que, al contrario de lo que sucede en nuestros días, el cómic seguía siendo la base de la popularidad del personaje, ya que, incluso en esas épocas de máxima audiencia, la serie nunca superó los cinco millones de oyentes frente a los treinta millones de lectores que tenía la tira de prensa, como ya se ha mencionado. ${ }^{22}$

Terry también llegó a la radio cuando Caniff fue entrevistado en programas como Wings over Nerw York, en marzo de 1944. Caniff, usando sus habilidades como actor, ${ }^{23}$ hizo una representación de la página dominical del 17 de octubre de 1943, con el discurso del Coronel Corkin cuando Terry se graduó en el Ejército del Aire. La vida del autor, cuya repercusión en ese momento era casi tan importante como su serie, fue narrada en la radio el 12 de mayo de 1944 en el programa Freedom of Opportunity, que cada semana honraba a uno de

${ }^{21}$ Ноraк, C. J. «Terry and the Pirates on Radio», en Caniffites, n. ${ }^{\circ} 40$ (1990), p. 7.

22 Datos recogidos de los datos de audiencia que la NBC le enviaba a Caniff y que se conservan en VV.AA. Terry Radio. Archivo de Milton Caniff en Billy Ireland Cartoon Library and Museum, Columbus, Ohio (EE. UU.). Box MAC.P88 / Folder 11.

${ }^{23}$ Caniff compaginaba, en sus años de universidad, su labor como dibujante con la actuación en diferentes obras de teatro. En su biografía se cuenta cómo en un momento dado tuvo serias dudas entre elegir entre una carrera como cartoonist o bien dedicarse a ser autor de teatro. Ver Harvey, R. C. Op. cit. pp. 36-105. 
los personajes más distinguidos de Estados Unidos. Parte de la introducción de ese programa es una muestra de la consideración que recibía Caniff de la población estadounidense, cuya presencia en la radio, junto a la del personaje, ayuda a la construcción de la perspectiva histórica referente a la relevancia social de la obra analizada:

Hay un joven que lucha en esta guerra en lo alto de las montañas Catskill, en un estudio cerrado, cada noche de la semana, cada semana del año. Con sus hombros apoyados sobre una mesa de dibujo, realiza pequeños bocetos con su mano izquierda. $Y$ algunos hombres en las trincheras, en barcos y en el aire, insisten en que esa mano izquierda está haciendo tanto por ganar la guerra como el rifle Garand. ${ }^{24}$

\section{Transposiciones}

El caso más claro de transposición de la serie fue su publicación en forma de libro. Hay que tener en cuenta que el carácter efímero del periódico hacía complicado, para un lector que se incorporara a la serie cuando esta ya llevaba meses o incluso años, acceder a las historias pasadas de sus personajes. Por este motivo, hay innumerables cartas en el archivo de Caniff pidiéndole la recopilación de los primeros episodios de la serie. Sin embargo, de forma prácticamente simultánea a la publicación de Terry y los piratas en la prensa, los lectores podían seguir las aventuras de los personajes de la serie en los Big Little Books publicados por Whitman Publishing Company y por Dell Publishing entre 1935 y 1942. Se trataba de libros de tamaño muy reducido, ${ }^{25}$ en cuyas páginas pares se realizaba, con bastante fidelidad, una adaptación en prosa de las aventuras ya publicadas en los periódicos, mientras que en las páginas impares se incluía una ilustración que correspondía con una viñeta directamente extraída de la serie. Este mismo procedimiento se siguió en las dos novelas sobre la serie publicadas durante la estancia de Caniff en la misma, April Kane and the Dragon Lady, publicada también por Whitman en 1942, y Terry and the Pirates, publicada por Random House en 1946, coincidiendo prácticamente con el final de la estancia de Caniff en la serie (FIG. 3). Se trataba también de adaptaciones en prosa de las historias de la tira, que incluían ilustraciones que se habían publicado originalmente en forma de tira o página dominical y que se habían remontado para su edición en libro. Sin embargo, la diferencia con los Big Little Books era que el número de ilustraciones era menor y el tamaño del libro mayor, por lo que la narración era más similar a la de una novela que en el caso de los libros pequeños, que se trataba más bien de resúmenes más o menos ampliados de la tira. De esta manera, las andanzas de Terry se podían seguir prácticamente en su totalidad en forma de libro y aumentar su periodo de permanencia en el mercado, lo cual facilitaba el acceso a los lectores.

${ }^{24}$ E1 M1 Garand (formalmente Fusil de los Estados Unidos, Calibre 30, M1) fue el primer fusil semiautomático de los Estados Unidos que llegó a ser un fusil común para la infantería. Oficialmente, reemplazaba al Springfield 1903 como fusil en servicio en 1936, hasta que fue reemplazado por el M14, que derivaba del M1, en 1957. La introducción al programa de radio Freedom of Opportunity se recoge en VV.AA. "A Tribute to Milton Caniff», en Magazine of Sigma-Chi. Febrero-marzo 1945, p. 65.

${ }^{25}$ Los Big Little Books tenían un tamaño de $11 \times 10 \mathrm{~cm}$, aproximadamente. 


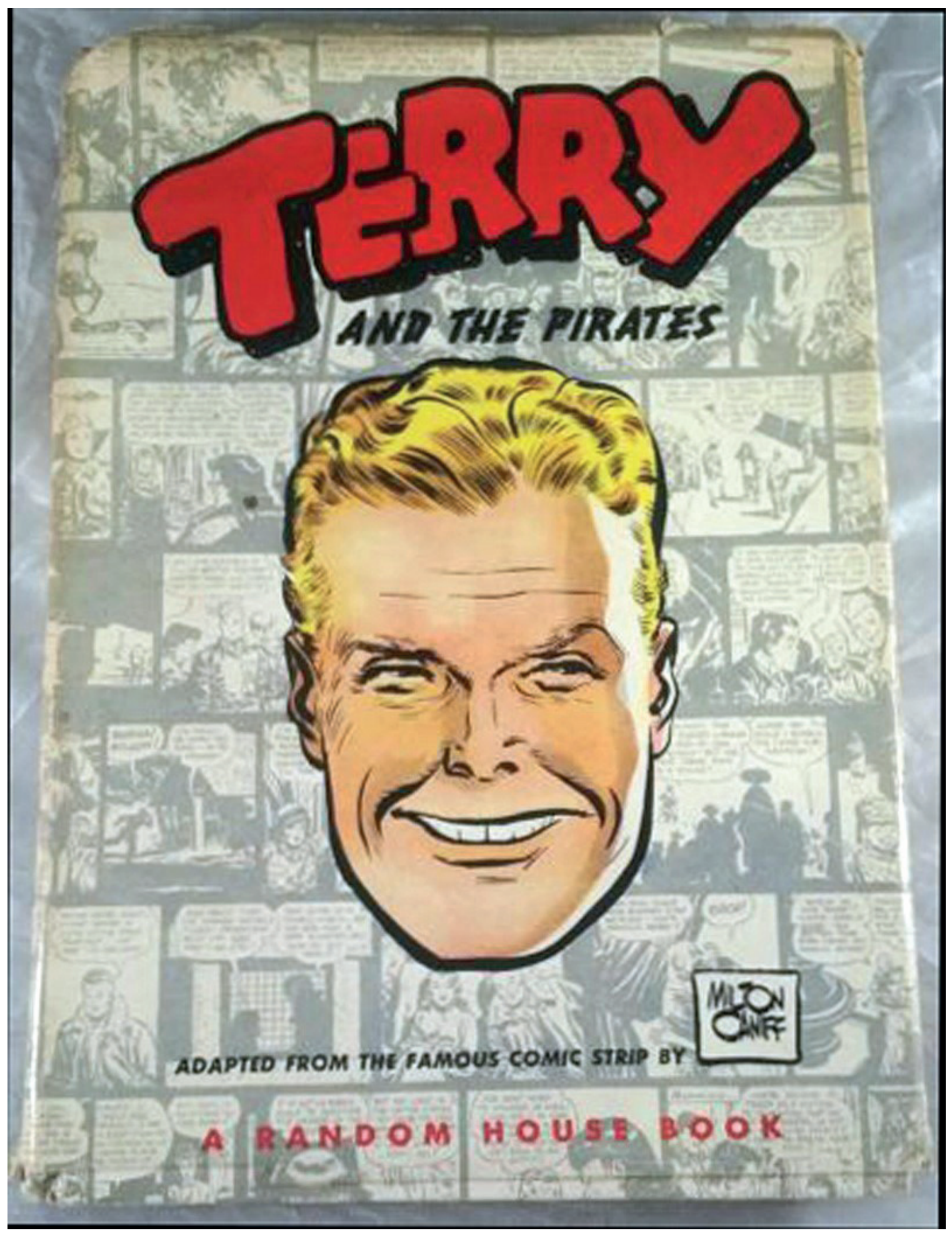

FIG. 3. Portada de la novela Terry y los piratas publicada en 1946 por Random House. Fuente: fotografía de dicha cubierta tomada por el autor. 
Por supuesto, como en la mayoría de las series populares de la época, hubo recopilaciones de las tiras en comic books. Durante los años en los que Milton Caniff estuvo al frente de la serie, Dell publicó tres números en su serie Large Feature Comic, que recopilaban las primeras aventuras aparecidas en los periódicos. Tuvo que ser cuando ya Caniff la había abandonado, en 1947, cuando Harvey inició una serie de comic books dedicada exclusivamente a la publicación de las historias de Terry y los piratas dibujadas por su creador. La serie se publicó irregularmente durante veintiocho números que aparecieron entre 1947 y 1955. Este, quizá, no sea exactamente un caso de transposición, ya que se editaba la misma historia que anteriormente se había publicado en los periódicos, remontada para la adaptación al nuevo formato y, en todo caso, con algún texto para facilitar la continuidad de una historia que, inicialmente, se publicaba de forma diaria. Sin embargo, había una percepción entre los autores y el público respecto a las diferencias entre las tiras de prensa y el comic book. ${ }^{26}$ En todo caso, en ningún momento se realizó ningún material inédito para su publicación en forma de comic book, más allá de algunas ilustraciones para las portadas, en las que Caniff nunca participó.

Sin embargo, en este periodo, pese al éxito de la serie, no se publicó ninguna historia original en forma de novela con los personajes de la serie. Probablemente, el motivo sea la existencia de un intento, por parte del propio Milton Caniff, de realizar una novela que nunca llegó a ver la luz. Su título era Terry and the Pirates and the Yangtze Raiders y el autor llegó a escribir un prólogo y tres capítulos en $1940 .{ }^{27} \mathrm{El}$ prólogo empieza así:

Los aviones vuelan en círculo por el cielo, como halcones. Hacen llover la muerte en la ciudad que está a sus pies. Un edificio tras otro estalla en violentas explosiones. Ancianos, mujeres y niños estallan en pedazos. Algunos yacen agonizando durante un tiempo, vertiendo su sangre vital. Otros encuentran una muerte rápida y misericordiosa. Las calles, llenas de cuerpos y ruinas, son un desastre. Miles mueren. Shanghái y Nanking caen. ${ }^{28}$

Hubo interés de L. C. Page \& Company, unos editores de Nueva York, por publicar la novela. Sin embargo, cuando Caniff envió el material realizado al editor, recibió la siguiente carta: «[Su capítulo de muestra] es, de alguna manera, más sangriento de lo que les gustaría a los bibliotecarios, profesores, etc. que controlan la compra de libros para jóvenes lectores». ${ }^{29}$

${ }_{26}$ Sobre este punto, es interesante acceder a las declaraciones de los autores de prensa ante el Subcomité del Senado para la Delincuencia Juvenil en 1954, como consecuencia, fundamentalmente, de la publicación del libro de Fredric Wertham, The Seduction of the Innocent. Como se puede ver en Harver, R. C. Op. cit. pp. 666-668, los autores de prensa tenían una consideración distinta de su trabajo, mucho más artístico, en contraposición con el trabajo del autor de comic book, considerado por ellos mucho más industrial.

${ }^{27}$ El hallazgo de esta novela es algo totalmente inédito, ya que ni siquiera se menciona en la biografía de Caniff. Al habla con los responsables de su archivo, estos indicaron que el autor de esa biografía, R. C. Harvey, cuando el material del mismo no estaba totalmente organizado y catalogado y, por ese motivo, hubo parte de su contenido al que no tuvo acceso, incluyendo esta novela.

${ }^{28}$ Caniff, M. Terry Novel (1940). Archivo de Milton Caniff en Billy Ireland Cartoon Library and Museum, Columbus, Ohio (EE. UU.). Box MAC.PS27 / Folder 56.

${ }^{29}$ Guy, E. P. Carta dirigida a Milton Caniff. Archivo de Milton Caniff en Billy Ireland Cartoon Library and Museum, Columbus, Ohio (EE. UU.). Box MAC.PS27 / Folder 56. 
Como sucedió en las adaptaciones cinematográficas y radiofónicas, los responsables, en este caso el editor, consideraban Terry y los piratas como una serie destinada al público infantil y querían que el libro pudiera ser leído por este tipo de público. Pese al desencuentro inicial, la editorial siguió interesada por el proyecto, a juzgar por las continuas cartas que enviaban a Caniff hasta marzo de 1942 interesándose por el estado del mismo, y ofreciéndose a contratar a un escritor que le ayudara a rebajar el tono de la historia inicial. Sin embargo, este proyecto nunca se materializó. Caniff adujo falta de tiempo para realizar los cambios sugeridos, pero probablemente existiera también un fuerte desánimo por parte del autor hacia el cambio de orientación mencionado, ya que él siempre consideró que su serie estaba dirigida al público adulto ${ }^{30}$ y ya había tenido una experiencia poco positiva con la adaptación de sus personajes al público infantil en el serial cinematográfico.

Para encontrar una adaptación de Terry y los piratas en formato de novela tenemos que llegar hasta el año 1949, cuando se publica Terry and the Pirates. The Jewels of Jade, escrita por Edward J. Boylan y publicada por Checkerbooks. Aunque hay unanimidad en afirmar que la calidad y el éxito de la serie disminuyeron significativamente tras la marcha de Caniff, los doce años iniciales de la misma habían creado lo que Hutcheon llama, siguiendo a Benjamin, un aura ${ }^{31}$ impregnada en el lector estadounidense, que facilitó que se siguieran produciendo diferentes adaptaciones en distintos medios, como es el caso de esta novela o la serie de televisión que se mantuvo durante muchos años, como se verá más adelante.

\section{Extensiones}

En 1935, Blue Ribbon Press publicó un libro en formato pop up titulado Terry and the Pirates in Shipwrecked (FIG. 4). Se incluye este libro en la parte de extensiones ya que su valor principal no era tanto la historia como la posibilidad de extender de forma lúdica el espíritu aventurero de la serie. Este objetivo se muestra más claramente en el juego de mesa de la serie que Whitman Publishing Company puso a la venta en 1937. Entre dos y cuatro jugadores competían para ver quién podía llevar primero su ficha de Terry al cofre del tesoro. Los jugadores encontraban obstáculos, ya que las casillas tenían reglas tales como «Terry avanza 1» 0 «Connie retrocede 1» (FIG. 5). Pero el juego más interesante desde el punto de vista intermedial era el Terryscope (FIG. 6). El Terryscope fue creado por los publicistas de Libby como gancho comercial para los oyentes de su programa de radio. ${ }^{32}$ De esta manera, «si envías una etiqueta de zumo de tomate y otra de zumo de piña de la marca Libby y 10 centavos adicionales, recibirás en tu casa el Terryscope», ${ }^{33}$ que una vez montado tenía imágenes de los personajes en los lados,

30 «Escribo la serie para el tío que compra el periódico». CAniff, M. «Don’t Laugh at the Comics». Cosmopolitan, noviembre 1958, p. 43.

31 Hutcheon, L. Op. cit., p. 4.

${ }^{32}$ Como se recoge en la carta enviada por los ejecutivos de esta compañía a Milton Caniff, conservada en VV.AA. Terry Radio. Archivo de Milton Caniff en Billy Ireland Cartoon Library and Museum, Columbus, Ohio (EE. UU.). Box MAC.P88 / Folder 11.

33 Esta frase se incluía al inicio de todos los programas del serial radiofónico en los años 1939 y 1940. 
un panel para el código secreto y un telescopio que daba nombre al juguete. Lo interesante no es solamente que se dedicara buena parte del espacio publicitario del programa de radio a las instrucciones necesarias que los oyentes tenían que seguir para obtener el Terryscope, sino que el propio argumento del serial incluía el juguete como una parte importante del mismo, poniendo a Terry en peligros que solo podían ser resueltos mediante el uso de ese instrumento, ${ }^{34}$ lo que, obviamente, aumentaba el deseo de los oyentes infantiles y hacía que, como decían los propios anuncios, los niños se lo "pidieran a sus padres». ${ }^{35} \mathrm{Se}$ creaba así una experiencia intermedial a través del Terryscope, ya que se podía escuchar el serial o jugar con el juguete de forma independiente, pero el acceso simultáneo de ambos productos derivados de la serie aumentaba la experiencia del aficionado infantil al que supuestamente estaba dirigido el serial.

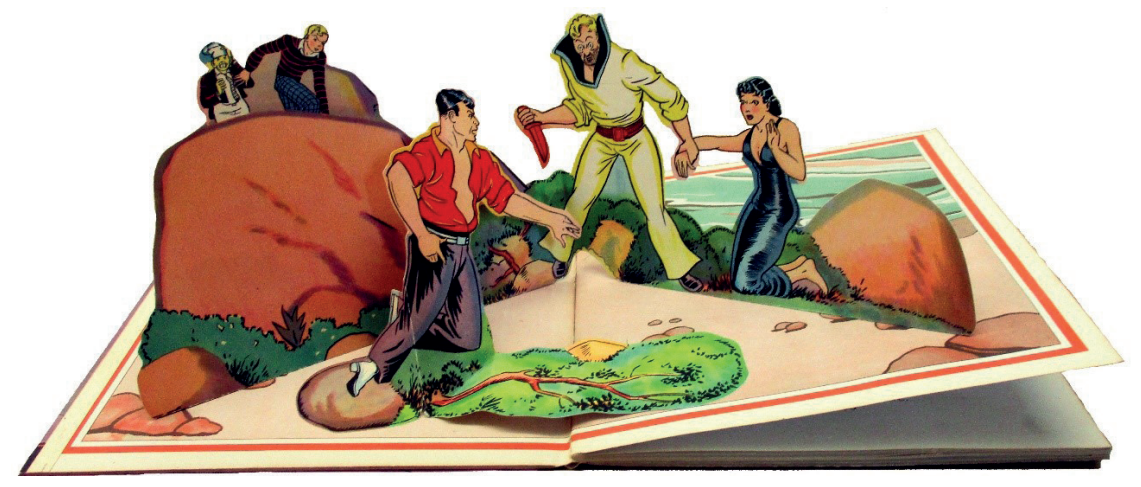

FIG. 4. Imagen del pop up de Terry y los piratas. Fuente: VV.AA. Terry Novelties, Books, etc. 19381941. Archivo de Milton Caniff en Billy Ireland Cartoon Library and Museum, Columbus, Ohio (EE. UU.). Box MAC.P87 / Folder 12.

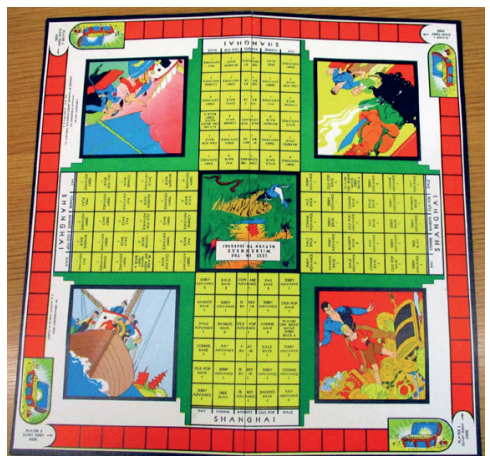

FIG. 5. Tablero del juego de mesa de Terry y los piratas. Fuente: VV.AA. Terry Novelties, Books, etc. 1938-1941. Archivo de Milton Caniff en Billy Ireland Cartoon Library and Museum, Columbus, Ohio (EE. UU.). Box MAC.P87 / Folder 12.

${ }^{34}$ El Terryscope permitía, en el serial, tanto observar a los enemigos sin que estos se dieran cuenta, como descifrar mensajes en código, mediante la información contenida en el interior del juguete.

35 De nuevo se trata de una frase incluida al inicio de todos los programas del serial radiofónico en los años 1939 y 1940. 


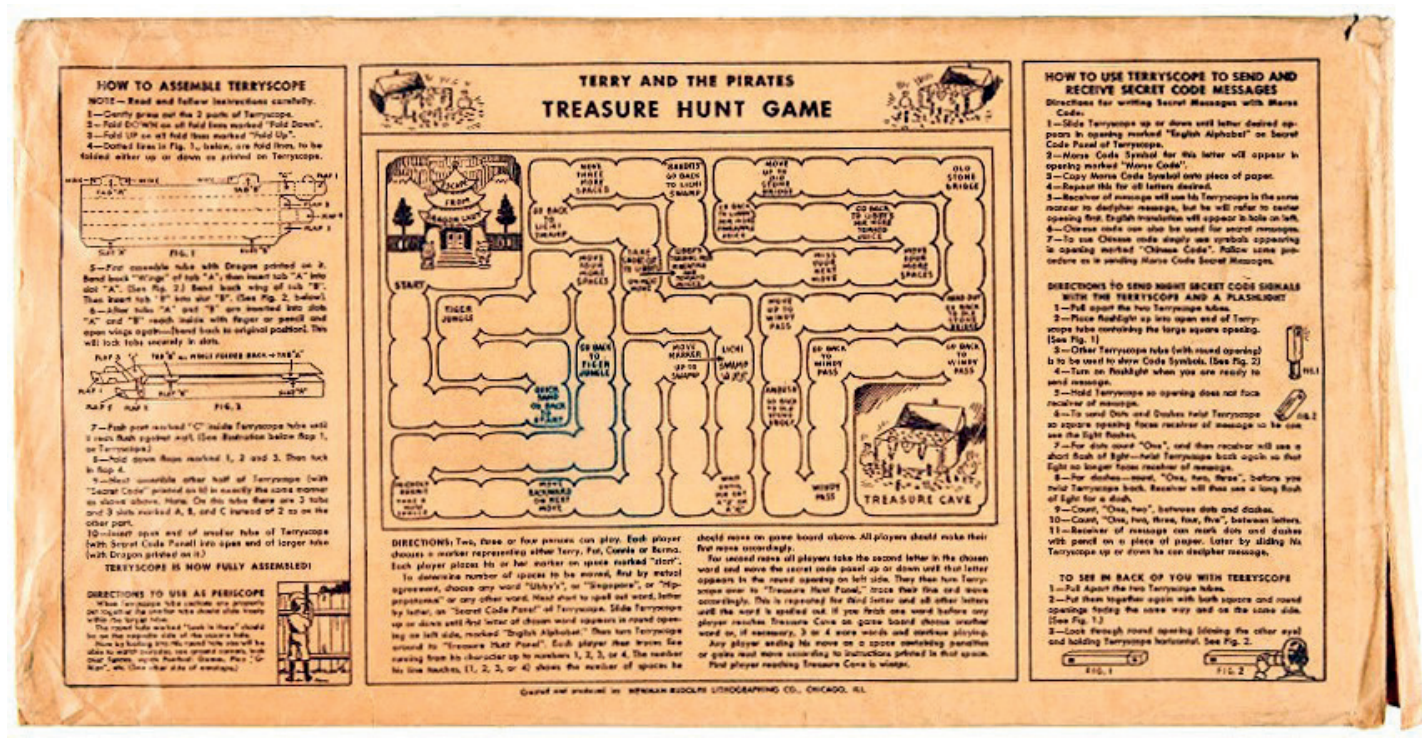

FIG. 6. Imágenes del Terryscope, antes y después de su montaje. En la parte interior, aparecían elementos que se podían utilizar para resolver enigmas planteados en el programa de radio. Fuente: VV.AA. Terry Novelties, Books, etc. 19381941. Archivo de Milton Caniff en Billy Ireland Cartoon Library and Museum, Columbus, Ohio (EE. UU.). Box MAC.P87 / Folder 12.

\section{Terry y los piratas después de Caniff}

Después de la partida de Caniff de la serie, con la página dominical del 29 de diciembre de $1946,{ }^{36}$ la serie continuó publicándose bajo el mando creativo de George Wunder, hasta que se canceló el 25 de febrero de 1973. Autores como Maurice Horn, consideran que la marcha de Caniff convirtió a la tira en una serie fantasma, ${ }^{37}$ ya que durante los años de Wunder la calidad y la popularidad de la serie fueron decreciendo paulatinamente. Sin embargo, el recuerdo de la etapa de Caniff siempre estuvo presente y el aura que había dejado el trabajo de Terry propició que siguieran apareciendo productos derivados, como la serie televisiva y la novela, ya mencionadas. Incluso, en el año 1980 hubo un intento de realizar una película, de la que incluso se realizó una campaña publicitaria que no fructificó (FIG. 7).

Más de veinte años después de la cancelación de la serie, el 26 de marzo de 1995, el productor cinematográfico Michael Uslan (encargado del guion) y los artistas Greg y Tim Hildebrandt lanzaron una nueva versión en forma de tira de prensa de Terry y los piratas,

${ }^{36}$ En realidad, la última imagen que Caniff dibujó de la serie fue la tira diaria del día anterior, ya que, por la complejidad del coloreado de las páginas dominicales, estas se dibujaban con una anterioridad de uno o dos meses con respecto a las tiras diarias.

37 Horn, M. y Couperie, P. A History of the Comic Strip. New York, Crown, 1968, p. 102. 


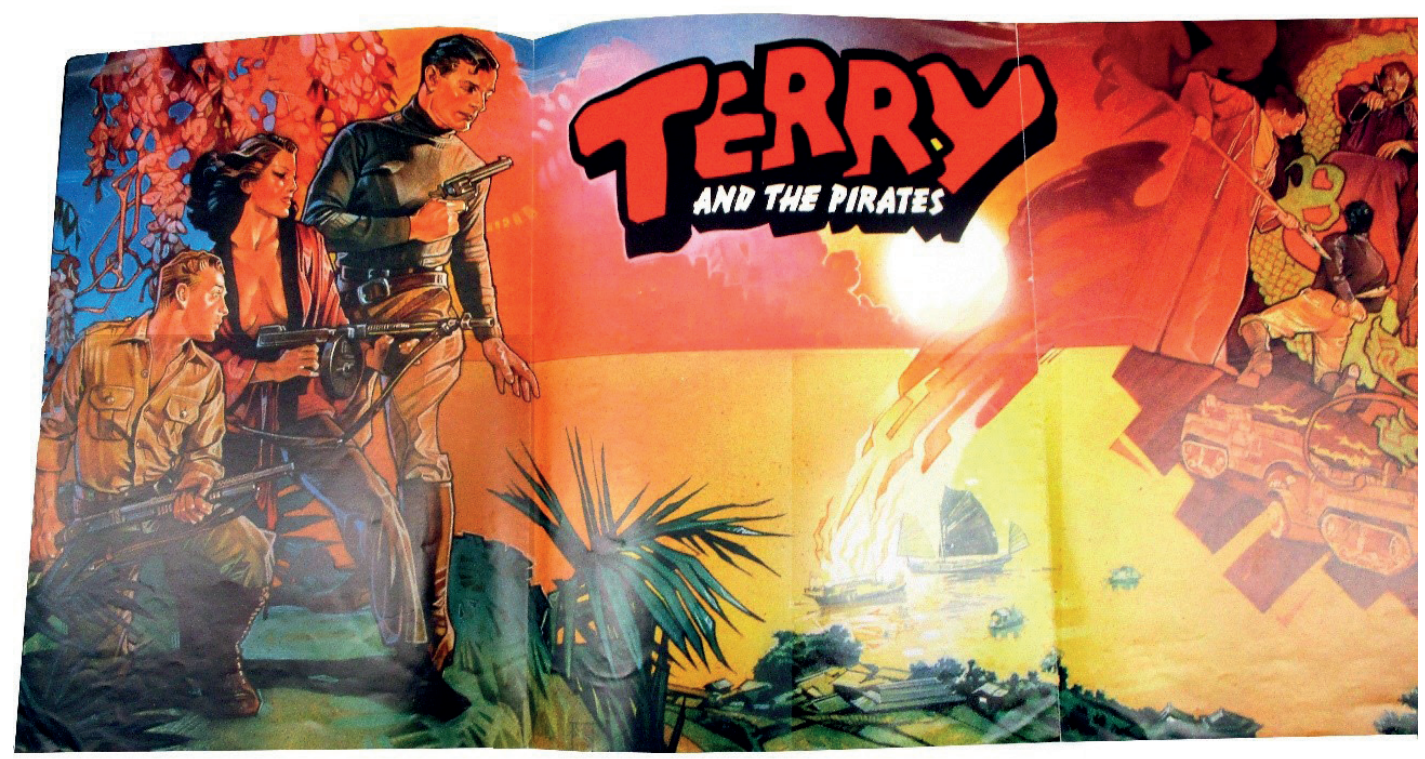

FIG. 7. Imagen promocional de la película de Terry y los piratas de 1980, nunca realizada. Fuente: VV.AA. Advertisements. Archivo de Milton Caniff en Billy Ireland Cartoon Library and Museum, Columbus, Ohio (EE. UU.). Box MAC.PS37 / Folder 33.

que tenía la particularidad de empezar de cero, adaptando los personajes a los años noventa (FIG. 8). Se trataba de una apuesta fuerte, ya que Michael Uslan tenía una posición importante en la industria del cine tras haber sido productor ejecutivo del Batman de Tim Burton y sus dos primeras secuelas. Por su parte, los hermanos Hildebrandt eran conocidos por sus ilustraciones para obras de fantasía y ciencia ficción. Como muestra de ese aura mencionada, relativa al trabajo de Caniff en Terry y los piratas, es interesante comprobar cómo, casi cincuenta años después de que Caniff abandonara la serie y tras un periodo de treinta y un años en los que George Wunder llevó las riendas de la misma, los tres reconocían su interés en reavivar la tira porque «habían crecido leyendo el cómic de Milton Caniff». ${ }^{38}$ En dicha versión, Terry es un joven de Hong Kong que forma equipo con Pat Ryan, siendo ambos reclutados por una organización del gobierno para luchar contra el grupo criminal comandado por Dragon Lady, en este caso, una huérfana de la guerra del Vietnam. Es curioso que en ningún momento se pensó en llevar a Terry de vuelta a 1930, porque el sentimiento de Uslan es que George Lucas y Steven Spielberg se habían inspirado en gran medida por Terry en la imaginería incluida en su película Indiana Jones. Según Uslan, «nos dimos cuenta de que si llevábamos a Terry de regreso a los años treinta, la gente pensaría que estábamos copiando Indiana Jones. Es un dilema irónico. Como resultado nos dimos cuenta de que la única forma de hacer la tira con éxito era en nuestros días». ${ }^{39}$

${ }^{38}$ Crouch, B. J. R. «Terry and the Pirates by Michael Uslan and Greg and Tim Hildebrandt», en Cartoonists Profiles, marzo de 1995, p. 27.

39 Idem. 


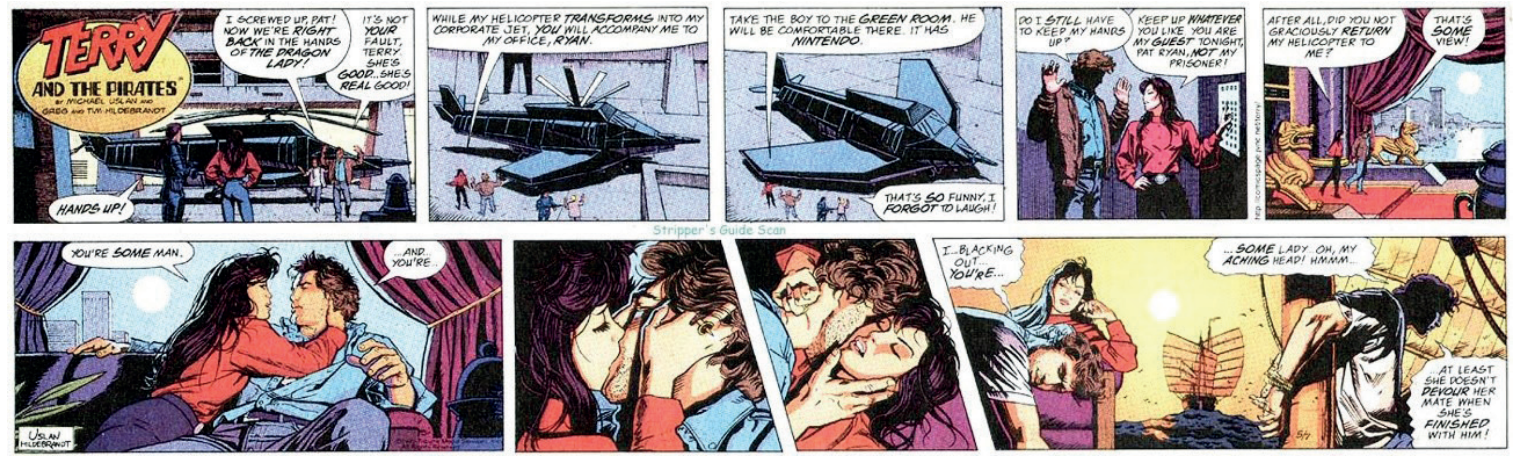

FIG. 8. Página dominical de la versión de 1995 de Terry y los piratas. Fuente: Crouch, B. J. R. «Terry and the Pirates by Michael Uslan and Greg and Tim Hildebrandt», en Cartoonists Profiles, marzo de 1995.

El concepto para Terry seguido por Uslan es el que tan bien le había funcionado junto con su compañero Benjamin Melniker en Batman. «Cogemos una propiedad y la hacemos emocionante y nostálgica para un adulto y también emocionante y nueva para un niño, así pueden compartir la experiencia. Si lo hacemos así, tenemos un ganador». ${ }^{40}$ Por tanto, uno de los objetivos de los creadores de esta nueva versión de Terry era convertir la serie en una franquicia, de forma similar a lo que estaba sucediendo con el hombre murciélago durante esos años. Esta idea nunca se pudo llevar a cabo, ya que la nueva encarnación de la tira no tuvo ningún éxito, posiblemente porque el momento de las tiras de prensa de aventuras ya había pasado, y los Hildebrandt abandonaron la serie el 1 de abril de 1996, siendo posteriormente cancelada el 27 de julio de 1997.

\section{Conclusiones}

El siglo Xxi ha cambiado en muchos aspectos el panorama de los medios artísticos y de comunicación. Estamos ante un periodo donde se construyen una serie de redes enormes de narraciones intermediales y transmediales. La tecnología y la proliferación de los medios de reproducción han permitido que diferentes productos, muchas veces provenientes de la cultura popular, hayan multiplicado su presencia en diferentes formatos, extendiendo el concepto de adaptación a algo mucho más complejo que ha despertado el interés de su estudio desde el punto de vista académico. Muchos de estos productos, que aparecen interpretados para múltiples medios y múltiples plataformas, tienen su origen en el mundo del cómic, con la creación de universos superheroicos y otras adaptaciones de series de cómic que traspasan su origen en las viñetas para llegar a diferentes productos derivados de sus personajes. El origen de este fenómeno no está muy claro, pero, de acuerdo con lo mostrado en la sección anterior, parece que hay una percepción, en cierta parte de la industria del entretenimiento, a que esta proliferación de adaptaciones en torno a un producto original comienza a finales

${ }^{40}$ Crouch, B. J. R. Op. cit., p. 27. 
del siglo xx. En esa sección, cuando se comenta el objetivo explícito de crear una franquicia derivada del lanzamiento de una nueva versión de una serie como Terry y los piratas en el año 1995, los referentes que se toman son otras franquicias muy próximas en el tiempo, como puede ser la creada alrededor de Batman, y se explica como algo novedoso y propio de ese periodo.

Sin embargo, para llegar a ese momento de finales del siglo xx, que evolucionaría en el panorama actual de transgresiones mediales centradas en torno a productos provenientes de la narrativa gráfica, es importante ofrecer una perspectiva histórica, de cómo ese fenómeno se ha producido en otras épocas. Esta idea es una muestra de la necesidad de la reconstrucción realizada en este artículo. Terry y los piratas ya era una franquicia en los años cuarenta. Una franquicia derivada, además, del éxito de la serie de prensa que, en todo momento, era el producto central y de mayor popularidad. La adaptación de las obras de éxito se ha producido siempre, pero solo las obras artísticas y culturales más importantes de su tiempo han sido capaces de generar un gran volumen de recreaciones, transposiciones y extensiones. Las series de cómic de prensa fueron un ejemplo de esta capacidad de creación de una franquicia, que precede históricamente a la aparición de otros fenómenos más actuales, como los superhéroes. Existe, por tanto, una necesidad de recuperación histórica de los cómics publicados en prensa, no ya desde un punto de vista artístico, sino desde un punto de vista de fenómenos sociales derivados de su enorme éxito, con el fin de mostrar, con perspectiva, la relevancia de estos cómics en su momento de publicación. Una labor a la que trata de contribuir este artículo centrándose en una de las series más significativas de los años treinta y cuarenta, como es Terry y los piratas. Se trata, por tanto y en cierta manera, de incluir en la historiografía del cómic su capacidad como creador de una serie de transgresiones mediales que nos permitan entender el momento actual, donde este fenómeno se ha incrementado de manera notable. El debate sobre las constelaciones intermediales derivadas del cómic no debe, por tanto, reducirse a las producciones contemporáneas, sino que tiene una historia que merece ser estudiada. 


\section{Bibliografía}

Bird, C. The Invisible Scar. New York, David McKay Company, 1966.

Caniff, M. «Don't Laugh at the Comics», en Cosmopolitan, noviembre 1958, pp. 43-47.

Coma, J. (Ed.) Historia de los cómics, vol. 1. Barcelona, Toutain, 1984.

- Cuando la inocencia murió. Ensayo sobre la obra de Milton Caniff «Terry y los piratas». Madrid, Ediciones Eseuve, 1986.

Crouch, B. J. R. «Terry and the Pirates by Michael Uslan and Greg and Tim Hildebrandt», en Cartoonists Profiles, marzo de 1995, pp. 25-35.

Dunning, J. Tune in Yesterday: The Ultimate Encyclopedia of Old-Time Radio, 1925-1976. New Jersey, Prentice Hall, 1976.

Fornaroli, E. Milton Caniff. Un filmico pennello tra il nero e il merletto. Florencia, La Nova Italia, 1988.

Goodman, J. (Ed.). While You Were Gone. A Report in War Life in the United States. Nueva York, Simon and Schuster, 1946.

Harvey, R. C. Meanwhile... A biography of Milton Caniff, creator of Terry and the Pirates and Steve Canyon. Seattle, Fantagraphics Books, 2007.

Hayward, J. P. Consuming Pleasures: Active Audiences and Serial Fictions from Dickens to Soap Opera. Lexington, University Press of Kentucky, 1997.

Horak, C. J. «Terry and the Pirates, the Serial», en Caniffites, n. ${ }^{\circ} 37$ (1989), pp. 7-10. — «Terry and the Pirates on Radio», en Caniffites, n. ${ }^{\circ} 40$ (1990), pp. 7-8.

Horn, M y Couperie, P. A History of the Comic Strip. New York, Crown, 1968.

Hutcheon, L. A Theory of Adaptation. New York, Routledge, 2006.

Meyer, C. «Medial transgressions: comics - sheet music - theatre - toys», en Journal of Graphic Novels and Comics, vol. 7, n. 3 (2016), pp. 293-305.

VV. AA. «A Tribute to Milton Caniff», en Magazine of Sigma-Chi, febrero-marzo 1945.

Waugh, C. The Comics. Jackson, University Press of Mississippi, 1947. 